\title{
Synergistic topical application of salt-processed Phellodendron amurense and Sanguisorba officinalis Linne alleviates atopic dermatitis symptoms by reducing levels of immunoglobulin $\mathrm{E}$ and pro-inflammatory cytokines in NC/Nga mice
}

\author{
SUNMIN PARK, DA SOL KIM, SUNA KANG and BAE KEUN SHIN \\ Department of Food and Nutrition, Obesity/Diabetes Research Center, Hoseo University, \\ Asan, Chungnam 336-795, Republic of Korea
}

Received November 18, 2014; Accepted August 19, 2015

DOI: $10.3892 / \mathrm{mmr} .2015 .4348$

\begin{abstract}
Atopic dermatitis is a chronic inflammatory skin disease, and salt-processed Phellodendron amurense (CPE) and Sanguisorba officinalis Linne (SOE) are widely used as anti-inflammatory agents in Asia. Therefore, the present study investigated the efficacy of CPE, SOE, and CPE+SOE in the treatment of atopic dermatitis-like symptoms in mice. Following topical application of 1,3-butylen glycol (control), $30 \%$ CPE, $30 \%$ SOE, $15 \%$ CPE $+15 \%$ SOE or $0.1 \%$ hydrocortisone $(\mathrm{HC})$ on the atopic dermatitis-like skin lesions of 2,4-dinitrochlorobenzene-treated NC/Nga mice for 5 weeks, the severity of clinical atopic dermatitis, mast cell infiltration, serum expression levels of immunoglobulin (Ig)E, IgG1, interleukin (IL)-4 and interferon (IFN)- $\gamma$, and cytokine expression in the dorsal skin were measured. Compared with the control group, treatment with CPE alleviated the clinical severity of the AD symptoms, with decreased numbers of mast cells, decreased expression levels of serum tumor necrosis factor (TNF)- $\alpha$, IL-4 and IFN- $\gamma$, and decreased expression levels of inflammatory cytokines in the dorsal lesions. Treatment with SOE did not reduce these expression levels, however, the serum expression levels of IgE and IgG1 were suppressed to similar levels as those in the CPE group. Furthermore, synergistic treatment with CPE and SOE relieved the clinical severity of atopic dermatitis, reduced the serum expression levels of IgE, IgG1, TNF- $\alpha$, IL-4 and IFN- $\gamma$, and suppressed
\end{abstract}

Correspondence to: Dr Sunmin Park, Department of Food and Nutrition, Obesity/Diabetes Research Center, Hoseo University, 29-1 Sechul-Ri Baebang-Myun, Asan, Chungnam 336-795, Republic of Korea

E-mail:smpark@hoseo.edu

Key words: atopic dermatitis, immunoglobulin E, mast cells, interleukin 4, processing Phellodendron amurense with salt, Sanguisorba officinalis Linne the mRNA expression levels of TNF- $\alpha$, IL-4, IL-13, and IFN- $\gamma$ in the dorsal skin lesions. Treatment with CPE+SOE was superior to treatment with $\mathrm{HC}$ alone for reducing dermal thickness and suppressing the production of several cytokines. Therefore, combined treatment with CPE and SOE may be an effective alternative intervention for the management of atopic dermatitis.

\section{Introduction}

Since the beginning of the twentieth century, the prevalence of mucosal inflammatory diseases, including atopic dermatitis, has been increasing. atopic dermatitis is more common in infants and children (10-20\%) than in adults (1-3\%) in developed countries (1), and its prevalence has markedly increased over the last 30-40 years. The onset of atopic dermatitis is associated with genetic and environmental factors, including a younger age, and living in urban areas and climates with low humidity $(2,3)$.

Atopic dermatitis is a common skin disease characterized by itching, dryness and skin rashes (4). Although the exact cause of atopic dermatitis remains to be elucidated, it develops following an abnormal reaction to irritants, including foods and environmental allergens, which are specific to each individual (2). There is no known cure for atopic dermatitis, and treatments are limited to improving or suppressing the symptoms. Since the disease is associated with inflammation and immune dysfunction, combined treatment with antibiotics and corticosteroids have reportedly been effective (5). However, this treatment strategy does not cure the disease, and cannot be used long-term due to their adverse effects (5). The application or topical corticosteoid cream produces stretch marks and thinning of the skin, which compromises epidermal barrier function, and increases sensitivity to contact allergens and infection by Staphylococcus aureus (6). Other immunosuppressants, including tacrolimus and pimecrolimus, are also used as topical preparations in the treatment of severe atopic dermatitis, and oral immunosuppressant medications, including ciclosporin, azathioprine and methotrexate 
are occasionally prescribed; however, these treatments have serious side effects, including liver and kidney damage, and skin cancer (7). Therefore, the objective of atopic dermatitis treatment is to reduce the inflammation and hyperactivation of the immune response to specific allergens, without serious adverse effects.

Natural products have been examined for use as alternative atopic dermatitis treatments with potent efficacy and minimal side effects (8-10). Cortex phellodendri (CPE), an Asian traditional medicine prepared from Phellodendron amurense, has been used for treating abdominal pain, diarrhea, gastroenteritis, urinary tract infections and other diseases (11). Its principal components are berberine, obacunone and obaculactone. Obaculactone has the unique immunomodulatory property of inhibiting the alloantigen-specific expression of T helper cell 1 (Th1) cytokines, interferon (IFN)- $\gamma$, proinflammatory cytokines, tumor necrosis factor (TNF)- $\alpha$, interleukin (IL)-2, and IL-6 in mice with skin allografts (12). The predominant function of CPE and its components is suppressing inflammation and scavenging free radicals $(9,11,12)$. CPE is prepared by drying and salt processing, during which the bioactive components are altered. A previous study demonstrated that the contents of obacunone and obaculactone are significantly different, according to the different processing methods (13). The contents of obaculactone are increased relative to those of obacunone in wine-fried and salt-fried products of CPE, compared with raw products (13). Therefore, processing CPE with salt may improve its efficacy for treating atopic dermatitis, compared with dried unprocessed CPE. Sanguisorba officinalis (SOE; great burnet) is known to cool the blood, inhibit bleeding, decrease temperature and heal wounds, and may be useful in the treatment of AD (14). A previous study demonstrated that SOE has similar effects to CPE, and exhibits anti-inflammatory, anti-oxidant and immunomodulatory activities (15). The predominant components of SOE are saponins, including triterpenes and their glycosides that include ziyuglycoside I, gallic acid and disaccharide ([5-O- $\alpha$-D-[3-C-hydroxymethyl]lyxofuranosyl- $\beta$-D-[2-C-hydr oxymethyl] arabino furanose) (15).

Therefore, the present study hypothesized that salt-processed CPE and SOE may alleviate atopic dermatitis by improving anti-inflammatory and immunomodulatory activity levels in experimental animals with AD. The present study examined the anti-atopic dermatitis activity levels of salt-processed CPE and SOE in 2,4-dinitrochlorobenzene (DNCB)-treated NC/Nga mice, and examined the mechanisms underlying the alleviation of atopic dermatitis symptoms.

\section{Materials and methods}

Preparation of extracts. Salt-processed CPE and SOE were purchased from Kyung-Dong Herb market (Seoul, Korea) in 2010, were confirmed by Dr Byung Seob Ko (Korean Herbal Medicine Institute, Daejeon, Korea), and voucher specimens (nos. 2010-04 and 2010-05) were deposited at the herbarium at the Department of Food and Nutrition, Hoseo University (Asan, Korea). Salt-processed CPE is commercially produced by boiling Phellodendron amurense bark and spraying the bark with $2 \%$ salt water prior to drying. Since 1,3-butylene glycol is an effective solvent for producing skin lotion (16), the salt-processed CPE and SOE (1 kg) were extracted at room temperature for $12 \mathrm{~h}$ using 3.3 liters of 1,3-butylene glycol (Sigma-Aldrich, St. Louis, MO, USA), prior to being filtered with filter paper (Watman; GE Healthcare, Little Chalfont, UK) and centrifuged at $450 \mathrm{x} \mathrm{g}$ at room temperature for $30 \mathrm{~min}$ to produce $30 \%$ extracts. Over $30 \%$ of the salt-processed extracts of CPE and SOE in 1,3-butylene glycol formed a precipitate. The supernatants were used for topical application in the subsequent experiments.

Determination of total phenol, flavonoid and alkaloid levels. The levels of total phenolic compounds of each $30 \%$ extract of salt-processed CPE and SOE were measured using Folin-Ciocalteu reagent (97.5\% purity; Sigma-Aldrich), and were expressed as mg gallic acid equivalents. $\mathrm{g}^{-1}$. The extracts were dissolved in ethanol and the total flavonoid contents were measured using a previously described method (17) with minor modifications. The extract was added to $2 \mathrm{~N} \mathrm{HCl}$ prior to being filtered. The solution was then mixed with bromocresol green solution (Sigma-Aldrich) and phosphate buffer (1:5:5) and the mixture was transferred to a separating funnel. Chloroform (Sigma-Aldrich) was subsequently added and mixed by vigorous agitation. The chloroform fraction was separated and its absorbance was measured at $470 \mathrm{~nm}$ using a UV/Visible spectrophotometer (Lambda 850; Perkin Elmer, Waltham, MA, USA). Berberine chloride ( $>90 \%$ purity; Sigma-Aldrich) was used as a standard. The total alkaloid content was expressed as mg berberine/g extract (18).

Animals. A total of 20 male six-week-old NC/Nga mice were purchased from Charles River Japan (Yokohama, Japan), and maintained in conventional conditions of a $12 \mathrm{~h}$ light/12 h dark cycle, room temperature of $22-23^{\circ} \mathrm{C}$ and humidity of $55 \pm 15 \%$. The mice had free access to food and water. All surgical and experimental procedures were performed according to the guidelines of the Animal Care and Use Review Committee of Hoseo University (Asan, Korea).

Induction of atopic dermatitis-like skin lesions. The mice were anesthetized with a mixture of ketamine and xylazine (100 and $10 \mathrm{mg} / \mathrm{kg}$ body weight, respectively; Bayer AG, Leverkusen, Germany), following which the hair on the back and right ear were shaved 1 day prior to sensitization. On the first day, $1 \%$ DNCB in acetone/olive oil ( $3: 1 ; 150 \mu 1$ per mouse) was applied to the dorsal skin and right ear, following which $0.2 \%$ DNCB (150 $\mu$ l per mouse) was applied every other day for five weeks, as previously described (10). The same volume of acetone/olive oil vehicle was applied, instead of the DNCB solution, to the controls. Repeated application of DNCB onto the dorsal region caused apparent dermatitis in the $\mathrm{NC} / \mathrm{Nga}$ mice (19).

Topical application of the 1,3-butylene glycol extracts of the salt-processed CPE and SOE were used to determine the effect of CPE and SOE on atopic dermatitis. Based on the preliminary cell-based investigations and the maximum dosage of the extract, two doses were assigned. The preliminary investigation demonstrated that 20 and $50 \mu \mathrm{g} / \mathrm{ml}$ of salt-processed CPE and SOE extracts, respectively, were effective against house mites (Arthropods of Medical Importance Resource Bank, Yonsei University, Seoul, Korea) in the 
Table I. Contents of phenolic compounds and flavonoids.

\begin{tabular}{lcr}
\hline Content & $\begin{array}{c}\text { Water extract of } \\
\text { Korean mistletoe } \\
(\mathrm{mg} / \mathrm{g} \text { dry weight })\end{array}$ & $\begin{array}{c}\text { Sanguisorba } \\
\text { officinalis } \\
(\mathrm{mg} / \mathrm{g} \text { dry weight })\end{array}$ \\
\hline Total phenols & $1.43 \pm 0.09$ & $71.4 \pm 2.37$ \\
Total flavonoids & $0.89 \pm 0.10$ & $75.5 \pm 3.57$ \\
Total alkaloids & $154 \pm 19$ & $0.08 \pm 0.01$ \\
\hline
\end{tabular}

Values are presented as the mean \pm standard deviation.

HaCaT human keratinocyte cell line (American Type Culture Collection; Manassas, VA, USA). Therefore, the topical application of $200 \mu 130 \%$ 1,3-butylene glycol was considered to be an effective dosage for use the animal model, when compared with a previous study (10). Following the induction of the atopic dermatitis-like skin lesions, the animals were divided into four groups, each containing 10 mice. The mice in these groups were then treated topically on the dorsal skin with a $200 \mu \mathrm{l}$ dose of one of the following four agents for five weeks: 1,3-butylene glycol (BG; control); 30\% CPE; 30\% SOE; $15 \% \mathrm{CPE}+15 \% \mathrm{SOE}$; or $0.1 \%$ hydrocortisone butyrate $(\mathrm{HC}$; Sigma-Aldrich; positive control) twice a day. Mice without induction of atopic dermatitis-like skin lesions were treated with 1,3-butylene glycol as a normal control. At the end of the study, rats were anesthetized with ketamine and xylazine (100 and $10 \mathrm{mg} / \mathrm{kg}$ body weight, respectively). Rats were sacrificed and tissues were collected for further experiments.

Evaluation of skin lesions. The relative dermatitis severity was assessed macroscopically using a previously described scoring procedure (20). The total skin severity scores were assessed weekly and defined as the sum of the individual scores for each of the following four symptoms: i) Erythema and hemorrhage, ii) edema, iii) erosion (excoriation) and iv) scaling (dryness). For each symptom, 0 was defined as exhibiting no symptoms, 1 as mild symptoms, 2 as moderate symptoms, and 3 as severe symptoms. To minimize technique variations, a single investigator performed the measurements throughout each experiment in a blinded-manner.

Measurement of serum levels of immunoglobulin (Ig)E and IgG1 and cytokines. Total serum levels of IgE and IgG1 were quantified using an ELISA Quantification kit (BD Biosciences, San Jose, CA, USA), according to the manufacturer's instructions. In addition, the serum concentrations of the TNF- $\alpha$, IL-4 and IFN- $\gamma$ cytokines were quantified using a Mouse Cytokine Enzyme Immunoassay kit (R\&D Systems, Minneapolis, MN, USA).

Reverse transcription-quantitative polymerase chain reaction (RT-qPCR). The dorsal skin tissue samples from five rats of each group were collected at the end of the experiment, and each skin tissue sample was individually powdered with a cold steel mortar and pestle, prior to being mixed with a monophasic solution of phenol and guanidine isothiocyanate (TRIzol reagent; Invitrogen Life Technologies, Carlsbad, CA, USA) for total RNA extraction, according to the manufacturer's instructions. The quantity and purity of RNA was measured at 260 and $280 \mathrm{~nm}$ using a Lambda 850 spectrophotometer (Perkin Elmer, Inc.) and cDNA was reverse transcribed from $1 \mu \mathrm{g}$ RNA extracted from the individual rats using a Superscript III Reverse Transcriptase kit (Invitrogen Life Technologies). A total of five cDNAs were produced from each group, and each cDNA was used for RT-qPCR. Equal quantities $(1 \mu \mathrm{g})$ of cDNA and primers for specific genes were mixed with SYBR $^{\circledR}$ Green (Bio-Rad Laboratories, Inc., Hercules, CA, USA) in duplicate, and amplified using a real-time PCR instrument (CFX Connect ${ }^{\mathrm{TM}}$ Real-Time PCR Detection System; Bio-Rad Laboratories, Inc.). The following thermocycling conditions were used to perform the PCR: $55^{\circ} \mathrm{C}$ for $2 \mathrm{~min}$, $95^{\circ} \mathrm{C}$ for $10 \mathrm{~min}$ followed by 40 cycles of $94^{\circ} \mathrm{C}$ for $20 \mathrm{sec}, 65^{\circ} \mathrm{C}$ for $30 \mathrm{sec}$ and $72^{\circ} \mathrm{C}$ for $20 \mathrm{sec}$. To assess which genes were associated with inflammation and degradation of articular cartilage, primers were used to detect the expression levels of rat-inducible nitric oxide synthase, TNF- $\alpha$, IL-1 $\beta$, IL- 6 , matrix metalloprotinase (MMP)-3, and MMP-13 genes, as previously described $(21,22)$. The cycle threshold (CT) for each sample was subsequently determined. The mRNA expression levels in the unknown samples were quantified using the comparative CT method ( $\triangle \Delta \mathrm{CT}$ method), as previously described by Livak and Schmittgen (23). $\Delta \mathrm{CT}$ was calculated using the following formula: $\Delta \mathrm{CT}=\mathrm{CT}$ (target gene) - CT (endogenous reference gene, $\beta$-actin). The relative fold-change in expression was calculated using the following equation: $\Delta \Delta \mathrm{Ct}=\Delta \mathrm{Ct}_{\text {treatment }}$ $\Delta \mathrm{Ct}_{\text {control. }}$. The results were presented as $2^{-\Delta \Delta \mathrm{CT}}$.

The following primers were used for the PCR reactions: MouseIFN- $\gamma$, sense 5'-CGGCACAGTCATTGAAAGCCTA-3' and antisense 5'-GTTGCTGATGGCCTGATTGTC-3'; IL-4, sense 5'-TCTCGAATGTACCAGGAGCCATATC-3' and antisense 5'-AGCACCTTGGAAGCCCTACAGA-3'; IL-13, sense 5'-CAGCTCCCTGGTTCTCTCAC-3' and antisense 5'-CCACACTCCATACCATGCTG-3'; TNF- $\alpha$, sense 5'-CCCTCACACTCAGATCATCTTCT-3' and anti-sense 5'-GCTACGACGTGGGCTACAG-3'; and $\beta$-actin, sense 5'-CATCCGTAAAGACCTCTATGCCAAC-3' and antisense 5'-ATGGAGCCACCGATCCACA-3'. The primers were designed to surround at least one intron in order to distinguish between the products derived from mRNA and genomic DNA.

Histologicalanalysis. Dorsal skintissue samples were harvested $24 \mathrm{~h}$ following final DNCB administration on day 35, and fixed in $10 \%$ buffered-neutral formaldehyde (Sigma-Aldrich) and embedded in paraffin wax (Leica Microsystems, Wetzlar, Germany). Histological skin tissue sections $(6 \mu \mathrm{m})$ were stained with hematoxylin and eosin (Sigma-Aldrich), in order to count the number of eosinophils. The sections were also stained with $0.5 \%$ toluidine blue (Sigma-Aldrich) in order to determine the number of mast cells. The cell counts were performed using microscope (Axio Imager 2; Carl Zeiss AG, Oberkochen, Germany) in six consecutive microscopic fields at x400 magnification.

Statistical analysis. Statistical analysis was performed using SAS software (version 9.3; SAS Institute Inc., Cary, NC, USA) and all results are expressed as the mean \pm standard deviation. 
The biological and metabolic effects of CPE, SOE, CPE + SOE, $\mathrm{HC}$ (positive control), and vehicle (negative control) were compared using one-way analysis of variance. Significant differences in the treatment effects among the groups were identified using Tukey's test. The significance of differences between the mice with and without atopic dermatitis-like skin lesion were determined using a two-sample Student's $t$-test. $\mathrm{P}<0.05$ was considered to indicate a statistically significant difference.

\section{Results}

Total phenol and flavonoid levels. CPE was predominantly composed of alkaloids, particularly berberine, and low levels of phenols and flavonoids. However, SOE was predominantly composed of phenols and flavonoids (Table I).

Clinical severity of skin lesions. Following repeated topical applications of DNCB on the backs of the NC/Nga mice atopic dermatitis lesions, the dorsal skin of the mice in the control group that developed DNCB-induced atopic dermatitis exhibited hypertrophy, hyperkeratosis, intercellular edema and liquefaction degeneration of the basal layer (data not shown). Clinical severity was calculated from the sums of the scores for erythema and hemorrhage, edema, erosion (excoriation) and scaling (dryness). The clinical severity of the skin lesions in the control group increased markedly until three weeks post-topical application of DNCB, however, no further exacerbated was observed at four weeks (Fig. 1). Hypertrophy, hyperkeratosis, intercellular edema and liquefaction degeneration of the basal layer in the dorsal skin tissue samples were alleviated by treatments with $\mathrm{CP}$ and SOE to a similar extent, and were alleviated more by SOE+CPE, compared with the control group (data not shown). Treatment with CPE and SOE decreased the severity of atopic dermatitis symptoms after four weeks. In addition, treatment with CPE and SOE synergistically slowed symptom progression and exhibited similar activity levels to treatment with $\mathrm{HC}$ over time (Fig. 1).

Expression levels of circulating IgE, IgGI,TNF- $\alpha, I L-4$ and INF- $\gamma$. Following topical application of DNCB onto the dorsal skin of the mice, the serum expression levels of IgE, an activator of mast cells, increased by $\sim 7$ and 15 -fold at 2 and 5 weeks, compared with the control. Compared with the control, the increase in serum levels of IgE were suppressed by treatment with SOE CPE, and suppressed further by treatment with SOE and CPE combined, compared with SOE and CPE alone, and this suppression level was similar to that induced by treatment with HC (Fig. 2A). Serum levels of IgG1 increased in the control group by 3.3 -fold after two weeks, and these expression levels decreased to 2.3 -fold after five weeks (Fig. 2B). Treatment with SOE, CPE, and CPE and SOE combined decreased the serum levels of IgG1, and the decrease in expression levels induced by treatment with CPE and SOE combined were similar to those observed following treatment with $\mathrm{HC}$ after 2 and 5 weeks (Fig. 2B). In addition, treatment with $\mathrm{CPE}$ and SOE combined, and treatment with $\mathrm{HC}$ decreased the serum expression levels of $\mathrm{IgG} 1$ to similar levels as the non-induction group.

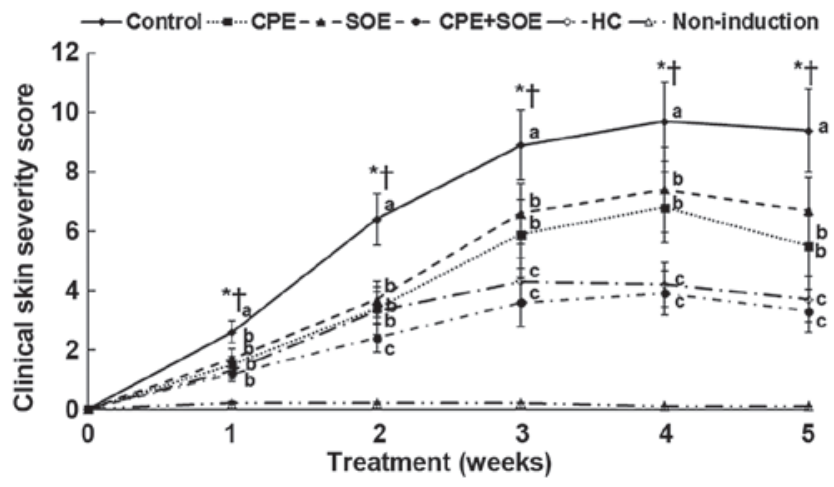

Figure 1. Changes in total skin severity scores of AD in NC/Nga mice. $\mathrm{AD}$ was induced in NC/Nga mice by topical application of DNCB to the dorsal skin and the ear, which was also topically treated with BG (control), $30 \%$ salt-treated CPE, $30 \%$ SOE, $15 \%$ CPE $+15 \%$ SOE, or $0.1 \%$ HC (positive control) on the lesions twice a day for five weeks. Mice without DNCB were treated with BG as a normal control. The total skin severity score was defined as the sum of the individual scores for each of the following four signs: i) Erythema and hemorrhage, ii) edema, iii) erosion (excoriation) and iv) scaling (dryness) every week. Score 0 , no symptoms; 1 , mild symptoms; 2 , moderate symptoms; 3 , severe symptoms. Each value represents the mean \pm standard deviation of 10 mice in each group. ${ }^{*} \mathrm{P}<0.05$, among the various treatments in $\mathrm{NC} / \mathrm{Nga}$ mice. ${ }^{\mathrm{a}-\mathrm{c}}$ Values with different superscripts were significantly different among the groups of $\mathrm{NC} / \mathrm{Nga}$ mice. ${ }^{\dagger} \mathrm{P}<0.05$, BG control, vs. non-induction control. AD, atopic dermatitis; DBCN, 2,4-dinitrochlorobenzene; $\mathrm{BG}, 1,3$-butylene glycol; $\mathrm{CPE}$, Cortex phellodendri; SOE, Sanguisorba officinalis; HC, hydrocortisone.

Mast cells secrete TNF- $\alpha$ and activate Th2-derived cytokines, including IL-4, IL-6 and IL-13. The serum levels of TNF- $\alpha$ in the control group increased significantly by 2.1 -fold, compared with those of the non-induction group (Fig. 2C). The levels of TNF- $\alpha$ expression levels were suppressed by treatment with CPE, however treatment with SOE and CPE combined inhibited them to similar levels as those induced following treatment with HC. In addition, the serum levels of IL- 4 and IFN- $\gamma$ were higher in the control group, compared with the non-induction group; IL-4 and IFN- $\gamma$ expression was suppressed by CPE, and this suppression was markedly increased by treatment with SOE and CPE combined, which reached similar expression suppression as that induced by treatment with HC (Fig. 2C). SOE also inhibited the serum expression levels of INF- $\gamma$, as compared with the control group, but did not inhibit the expression of IL-4. These results suggest that both $\mathrm{Th} 2$ and Th1 were activated during the experiment.

Histological findings and mast cell number in the inflamed skin tissue samples. As determined using histological staining, skin thickness was markedly higher in the control group, compared with the non-induction group. Treatment with CPE or SOE alone decreased skin thickness, however, treatment with SOE and CPE combined markedly decreased skin thickness to similar levels as treatment with $\mathrm{HC}$, as compared with treatment with SOE or CPE alone (Fig. 3A).

As seen in Fig. 3B, the infiltration of inflammatory cells, including mast cells and eosinophils was greater in the control group than in the normal control group that did not exhibit atopic dermatitis. The number of mast cells and eosinophils markedly increased in the skin lesions of the control group, compared with the non-induction group (Fig. 3C). SOE and CPE alone decreased the number of eosinophils in the 
A

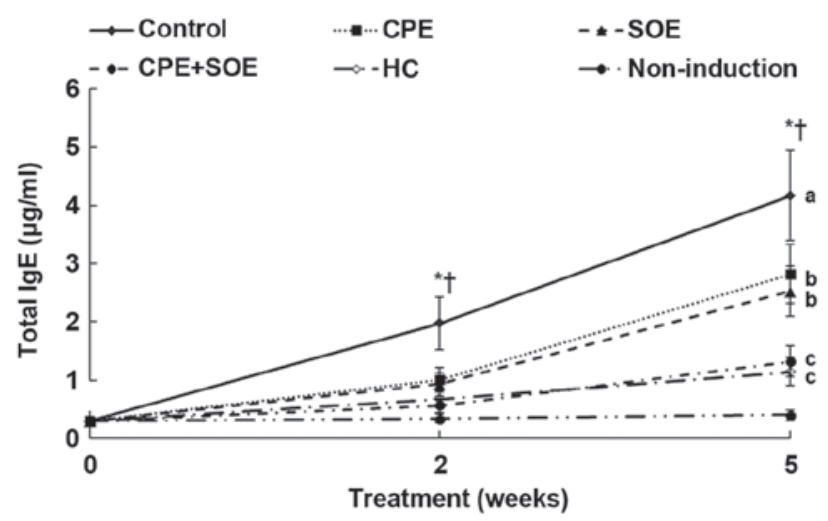

B

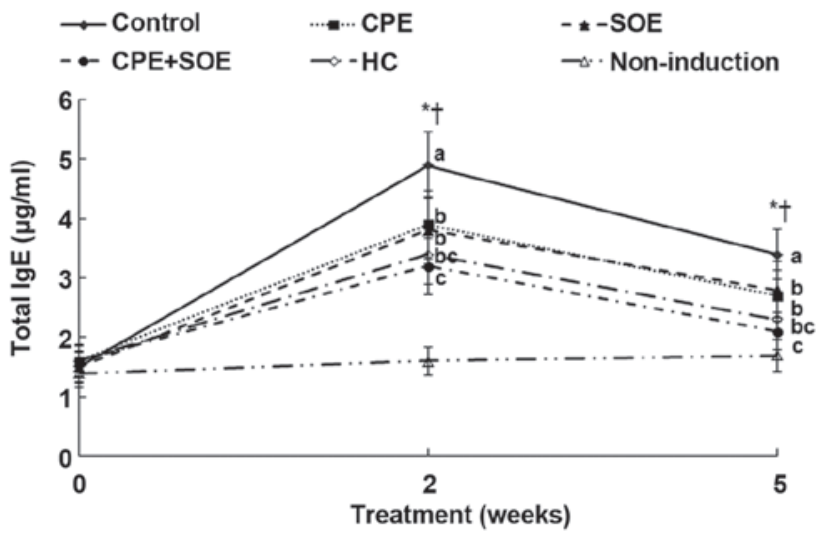

C

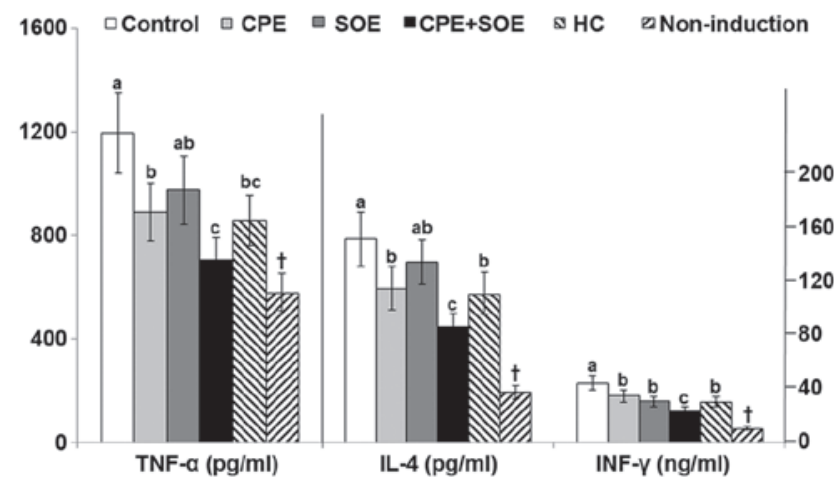

Figure 2. Serum levels of IgG1, IgE, IL-4 and IFN- $\gamma$ at the end of the experimental periods. AD was induced in NC/Nga mice by topical application of $\mathrm{DNCB}$ to the dorsal skin of the ear, which was also topically treated with BG (control), 30\% salt-treated CPE, 30\% SOE, 15\% CPE+15\% SOE, or $0.1 \%$ $\mathrm{HC}$ (positive control) on the lesions twice a day for five weeks. Mice without DNCB application were treated with BG as a normal control. Following five weeks of treatment, serum was separated to measure immunoglobulins and cytokines. (A) Serum levels of IgE. (B) Serum levels of IgG1. (C) Serum levels of TNF- $\alpha$, IL- 4 and INF- $\gamma$. Each value represents the mean \pm standard deviation of 10 mice in each group. ${ }^{*} \mathrm{P}<0.05$, among the various treatments in the $\mathrm{NC} / \mathrm{Nga}$ mice. ${ }^{\mathrm{a}-\mathrm{C}}$ Values with different superscripts were significantly different among the groups of $\mathrm{NC} / \mathrm{Nga}$ mice according to Tukey's test. ${ }^{\dagger} \mathrm{P}<0.05$, BG control, vs. non-induced control. AD, atopic dermatitis; Ig, immunoglobulin; IL, interleukin; IFN, interferon; DBCN, 2,4-dinitrochlorobenzene; BG, 1,3-butylene glycol; CPE, Cortex phellodendri; SOE, Sanguisorba officinalis; $\mathrm{HC}$, hydrocortisone.

DNCB-treated mice, and treatment with SOE+CPE further decreased the number of eosinophils, which was similar to that observed following treatment with HC. However, the
A

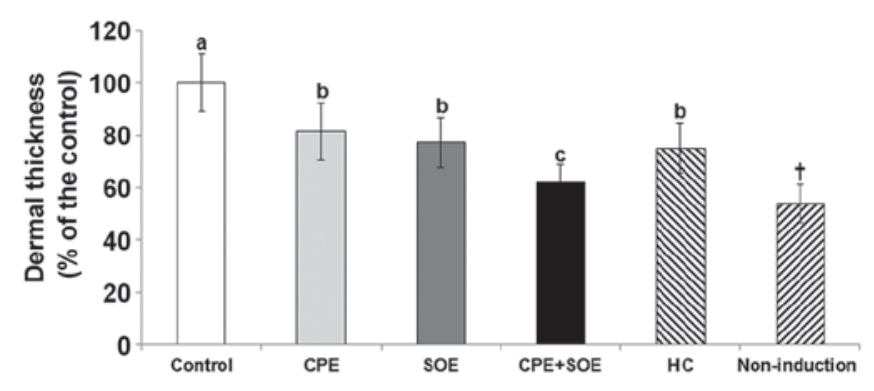

B
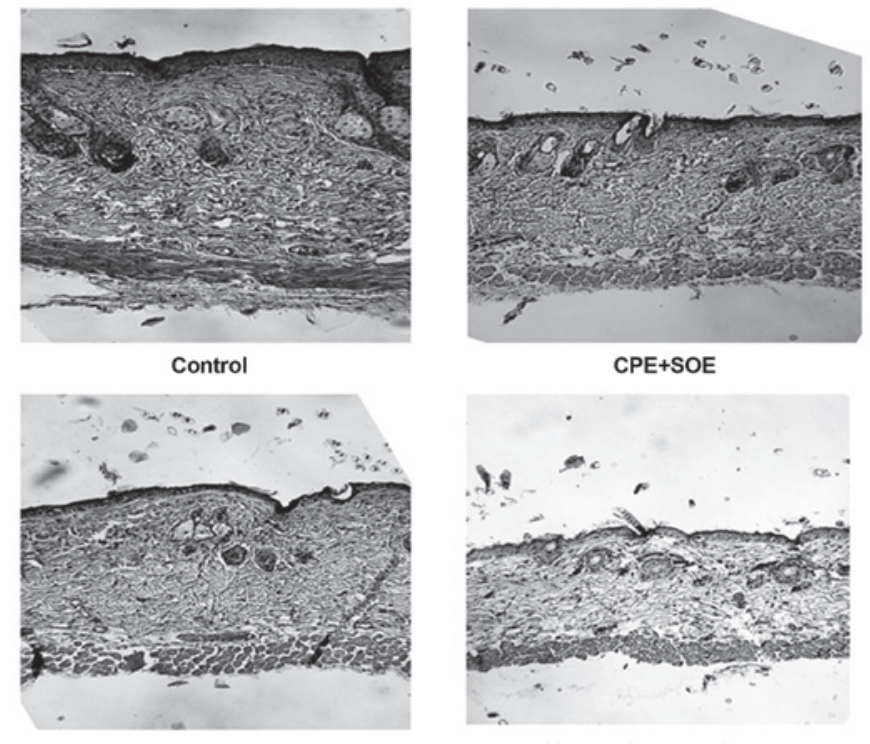

HC

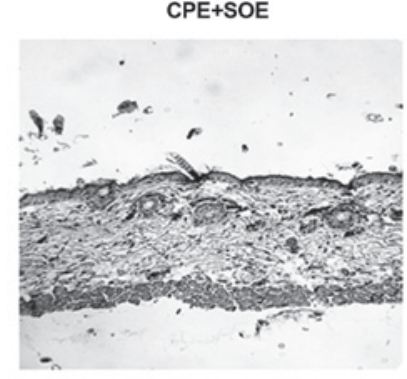

Normal control

C

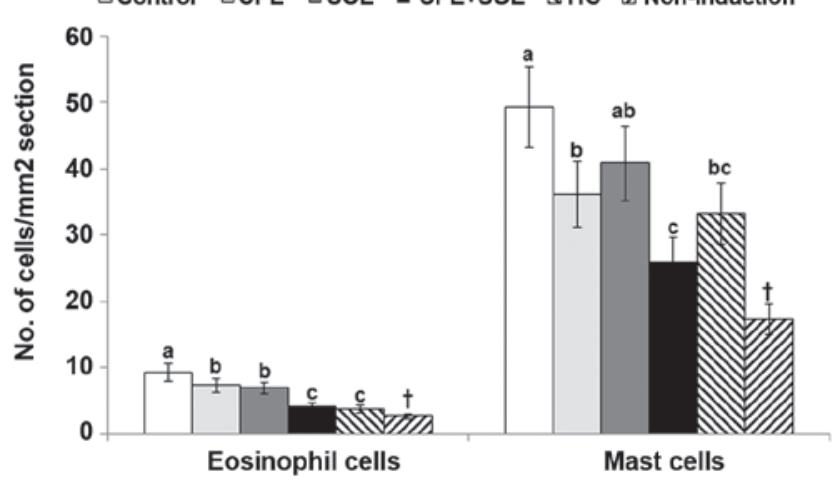

Figure 3. Numbers of mast cells and eosinophils in the dorsal skin, determined using histopathological analysis of $\mathrm{AD}$, which was induced in NC/Nga mice by the topical application of DNCB to the dorsal skin. The skin was also topically treated with either BG (control), 30\% salt-treated CPE, 30\% SOE, $15 \% \mathrm{CPE}+15 \% \mathrm{SOE}$, or $0.1 \% \mathrm{HC}$ (positive control) on the lesions twice a day for five weeks. Mice without DNCB application were treated with BG and used as a normal control. Following five weeks of treatments the dorsal skin was fixed with $10 \%$ formaldehyde and embedded in paraffin. The skin sections were stained with hematoxylin and eosin and toluidine blue, and the number of eosinophils and mast cells were counted under a microscope in the respective stained sections. Each value is expressed as the mean \pm standard deviation of five mice in each group. (A) Dermal thickness of the dorsal skin. (B) Histology of the dorsal skin sections following staining with hematoxylin and eosin (magnification, $\mathrm{x} 400$ ). (C) Number of eosinophils and mast cells. ${ }^{*} \mathrm{P}<0.05$ among the various treatments in the $\mathrm{NC} / \mathrm{Nga}$ mice. ${ }^{\mathrm{a}-\mathrm{c}}$ Values with different superscripts were significantly different among the groups of $\mathrm{NC} / \mathrm{Nga}$ mice according to Tukey's test. ${ }^{\dagger} \mathrm{P}<0.05 \mathrm{BG}$ control, vs. non-induced control. AD, atopic dermatitis; DBCN, 2,4-dinitrochlorobenzene; BG, 1,3-butylen glycol; CPE, Cortex phellodendri; SOE, Sanguisorba officinalis; HC, hydrocortisone. 
A

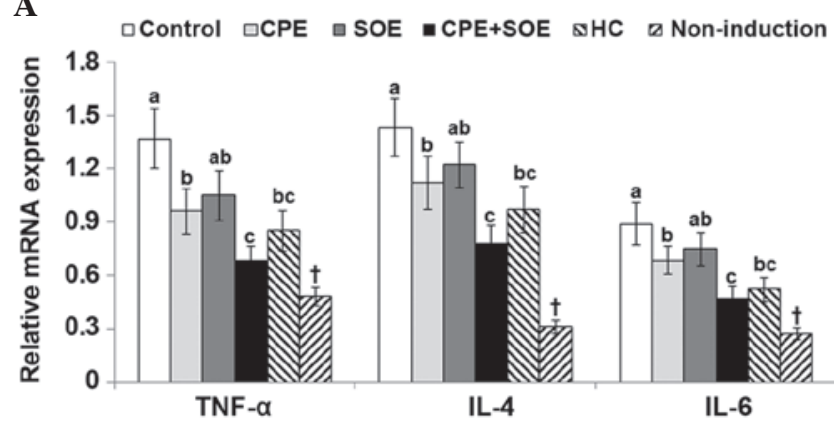

B $\square$ Control $\square \mathrm{CPE} \backsim \mathrm{SOE} \square \mathrm{CPE}+\mathrm{SOE} \quad \mathrm{BHC} \square$ Non-induction

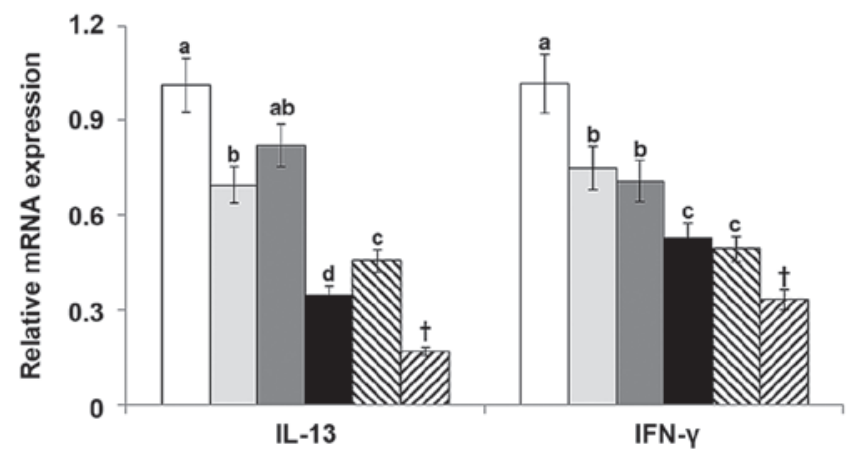

Figure 4. Expression levels of TNF- $\alpha$, IL-4, IL-6, IL-13 and IFN- $\gamma$ in the dorsal skin. $\mathrm{AD}$ was induced in $\mathrm{NC} / \mathrm{Nga}$ mice by topical application of DNCB to the dorsal skin of the ear, which was also topically treated with BG (control), $30 \%$ salt-treated CPE, $30 \%$ SOE, $15 \%$ CPE $+15 \%$ SOE, or $0.1 \%$ HC (positive control) on the lesions twice a day for five weeks. Mice without DNCB application were treated with BG as a normal control. Following five weeks of treatment, total RNA was extracted from the dorsal skin, from which cDNA was reverse transcribed. mRNA expression levels were measured using reverse transcription-quantitative polymerase chain reaction, and their relative expression levels were standardized according to respective mRNA levels of $\beta$-actin. Each value represents the mean \pm standard deviation of five mice in each group. (A) mRNA expression levels of TNF- $\alpha$, IL-4 and IL-6. (B) mRNA expression levels of IL-13 and INF- $\gamma$. ${ }^{\text {P }}<0.05$ among the various treatments in the $\mathrm{NC} / \mathrm{Nga}$ mice. ${ }^{\mathrm{a}, \mathrm{b}, \mathrm{P}} \mathrm{P}<0.05$ among $\mathrm{NC} / \mathrm{Nga}$ mice, determined using Tukey's test. ${ }^{\dagger} \mathrm{P}<0.05 \mathrm{BG}$ control, vs. non-induced control. $\mathrm{AD}$, atopic dermatitis; Ig, immunoglobulin; IL, interleukin; IFN, interferon; DBCN, 2,4-dinitrochlorobenzene; BG, 1,3-butylene glycol; CPE, Cortex phellodendri; SOE, Sanguisorba officinalis; HC, hydrocortisone.

number of mast cells was decreased by CPE, but not SOE, compared with the control group, whereas treatment with CPE and SOE synergistically inhibited the number of mast cells, and this decrease was marginally greater compared with treatment with $\mathrm{HC}$ (Fig. 3C).

mRNA expression levels of cytokines. To investigate cytokine production in the dorsal skin lesions, the mRNA expression levels of the TNF- $\alpha$, IL-4, IL-6, IL-13 and INF- $\gamma$ cytokines were quantified. The dorsal skin of the DNCB-treated control mice exhibited significantly higher expression levels of TNF- $\alpha$, IL-4, IL-6, IL-13, and IFN- $\gamma$, compared with those of the non-induction group (Fig. 4A and 4B). CPE, but not SOE, suppressed the mRNA expression of TNF- $\alpha$, IL-4, IL-6, IL-13 and IFN- $\gamma$, and treatment with $\mathrm{CPE}+\mathrm{SOE}$ further decreased their expression levels (Fig. 4A and 4B). The suppression of TNF- $\alpha$, IL-4, IL-6, IL-13 and IFN- $\gamma$ following treatment with
$\mathrm{CPE}$ and SOE combined was marginally more effective than treatment with the $\mathrm{HC}$ a positive control (Fig. 4A and 4B).

\section{Discussion}

The present study demonstrated that CPE alleviated the clinical severity of atopic dermatitis by decreasing the number of mast cells, as well as the serum levels of serum TNF- $\alpha$, IL-4 and IFN- $\gamma$ and various cytokines in the dorsal lesions of $\mathrm{NC} / \mathrm{Nga}$ mice, compared with the control group. However, $\mathrm{SOE}$ alone did not improve the clinical severity of atopic dermatitis, although serum levels of IgE and IgG1 were suppressed to similar levels as those observed following treatment with CPE. Treatment with CPE+SOE synergistically improved the clinical severity of the atopic dermatitis skin lesions by decreasing the serum levels of IgE, IgG1, TNF- $\alpha$, IL-4 and IFN- $\gamma$, and the mRNA expression levels of TNF- $\alpha$, IL-4, IL-13 and IFN- $\gamma$. The suppression of cytokine production by $\mathrm{CPE}+\mathrm{SOE}$ combined was marginally higher compared with that observed following treatment with HC. Therefore, these results suggested that CPE and SOE may be an effective alternative treatment strategy for the management of atopic dermatitis.

Atopic dermatitis is a chronic inflammatory skin disease that develops in response to specific antigens. The skin is a host defense system against microbial invasion and allergen penetration (1). Although the cause of atopic dermatitis remains controversial, defects in the epidermal barrier function contribute to the activation of the immune response and pro-inflammatory cytokine release, which results in atopic dermatitis $(1,2,4)$. Antigens disrupt the epidermal barrier and sensitize inflammatory dendritic epidermal cells to Th lymphocytes in the skin $(1,4)$. The Th cells release pro and anti-inflammatory cytokines that usually exacerbate the symptoms. Therefore, atopic dermatitis is treated predominantly with various emollients that improve skin appearance and dryness, or skin barrier repair and anti-inflammatory agents.

$\mathrm{NC} / \mathrm{Nga}$ mice is a well-known animal model for atopic dermatitis, and atopic dermatitis-like skin lesions induced by allergens in NC/Nga mice are similar to those in human atopic dermatitis (24). The symptoms of atopic dermatitis are erythema and hemorrhage, followed by edema, superficial erosion, deep excoriation, alopecia and dryness in the skin $(10,24)$. In the present study, DNCB-treated NC/Nga mice were used as an atopic dermatitis animal model. Although $\mathrm{NC} / \mathrm{Nga}$ mice are susceptible to developing atopic dermatitis, an allergen, such as $\mathrm{DNCB}$, is required in order to induce apparent symptoms. The mice in the control group developed moderate to severe symptoms of erythema and hemorrhage, edema, erosion (excoriation) and scaling (dryness). The clinical severity of the skin lesions were attenuated by CPE, and to a lesser extent by SOE, whereas treatment with CPE and SOE synergistically improved symptom severity. The clinical severity of atopic dermatitis was associated with the hyperproduction of circulating IgE by B lymphocytes and inflammatory cytokines from Th lymphocytes.

Among the clinical symptoms, itching is a common symptom of atopic dermatitis, and due to itching, scratching of the skin with toenails appears to be the crucial factor in causing dermatitis, and results in the elevation of serum concentrations of $\operatorname{IgE}$ and the number of mast cells (25). Serum levels of IgE are considered an important marker 
of atopic dermatitis, as the majority of patients with atopic dermatitis exhibit significantly elevated serum levels of $\mathrm{IgE}$, compared with patients with non-atopic dermatitis $(26,27)$. $\mathrm{IgE}$ binds to the surface of mast cells in order to induce the release of histamine and cytokines, which aggravate atopic dermatitis symptoms. In addition, atopic dermatitis lesions are dominated by infiltrating Th2 cells in the acute phase, which release cytokines, including IL-4, IL-5 and IL-13, whereas in chronic atopic dermatitis lesions, there is a switch towards a Th1 phenotype, which leads to IFN- $\gamma$ secretion (28). Several studies have demonstrated that patients with atopic dermatitis lesions exhibit elevated serum levels of IgE, TNF- $\alpha$, IL-4, IL-6 and INF- $\gamma$, compared with healthy individuals, indicating that Th2 and Th1 lymphocytes are activated in patients with atopic dermatitis $(21,29)$. Similar to these investigations in humans, the present study demonstrated that serum levels of IgE, TNF- $\alpha$, IL-4 and INF- $\gamma$ were significantly increased in the control mice that developed atopic dermatitis, and treatment with CPE and SOE synergistically lowered serum levels of IgE, as well as those of serum TNF- $\alpha$, IL- 4 and INF- $\gamma$. The results suggested that $\mathrm{NC} / \mathrm{Nga}$ mcie challenged with DNCB activated Th2 and Th1 lymphocytes at week 5 of the experimental period. The decrease in cytokine levels induced by CPE+SOE was greater, compared with $\mathrm{HC}$ treatment. Topical corticosteroid treatment is known to suppress the initial step, which activates Th lymphocytes and consequently suppresses the release of pro-inflammatory cytokines $(5,22)$. These results suggested that corticosteroids attenuated atopic dermatitis symptoms by inhibiting the initial step of Th lymphocyte activation and not by directly inhibiting the secretion of inflammatory cytokines. Therefore, treatment with $\mathrm{CPE}+\mathrm{SOE}$ may provide improved treatment for atopic dermatitis than corticosteroids.

Similar to serum levels of cytokines, allergens induce atopic dermatitis as a result of complex immune and inflammatory responses driven by the release of proinflammatory cytokines and chemokines in the skin. Inflammation damages the skin barrier and continues to elevate the levels of cytokines released from mast cells and Th2 and Th1 lymphocytes, thereby exacerbating atopic dermatitis $(29,30)$. The chronic phase of atopic dermatitis is characterized by lichenification of skin, infiltration of Th1 cells and tissue remodeling, with increased collagen deposition and dermal thickening (31). The histological observations of the present study demonstrated that the NC/Nga mice challenged with DNCB exhibited increased dermal thickness, and higher numbers of mast cells and eosinophils, compared with non-induced mice. These changes were associated with increased mRNA expression levels of cytokines, including TNF- $\alpha$, IL-4, IL-6, IL-13 and INF- $\gamma$ in the dorsal skin lesion samples. Previous studies have demonstrated similar results following herbal treatments of atopic dermatitis lesions $(8,10)$. The results of the present study also demonstrated that treatment with CPE+SOE synergistically reduced dermal thickness and the number of mast cells and eosinophils, whereas the mRNA expression levels of cytokines in the dorsal lesion were markedly suppressed by treatment with $\mathrm{CPE}+\mathrm{SOE}$. HG also improved dermal thickness and suppressed cytokine expression in the dorsal skin tissue lesions. However, treatment with CPE+SOE had more marked effects than treatment with $\mathrm{HG}$.

In conclusion, compared with the control group, treatment with CPE alone alleviated the clinical severity of atopic dermatitis symptoms, with decreased numbers of mast cells, serum levels of TNF- $\alpha$, IL-4 and INF- $\gamma$, and expression levels of cytokines in the dorsal lesions of the mice. However, treatment with SOE did not result in decreased expression levels, although serum levels of $\mathrm{IgE}$ and $\mathrm{IgG1}$ were suppressed to similar levels as those observed following treatment with CPE. Furthermore, treatment with CPE+SOE synergistically relieved the clinical severity of the symptoms, suppressed serum levels of IgE, IgG1, TNF- $\alpha$, IL- 4 and IFN- $\gamma$, and decreased the mRNA expression levels of TNF- $\alpha$, IL-4, IL-13 and IFN- $\gamma$ in the dorsal skin lesions. The improvements in symptoms following treatment with $\mathrm{CPE}+\mathrm{SOE}$ combined were more marked than those following treatment with $\mathrm{HC}$ in reducing dermal thickness and suppressing cytokine production. In conclusion, synergistic treatment with $\mathrm{CPE}+\mathrm{SOE}$ may be an effective alternative therapeutic strategy for the management of atopic dermatitis.

\section{Acknowledgements}

The present study was supported by the Academic Research fund of Hoseo University (Asan, China) in 2013 (no. 2013-0387).

\section{References}

1. Williams HC: Clinical practice. Atopic dermatitis. N Engl J Med 352: 2314-2324, 2005.

2. Leung DYM: New insights into the complex gene-environment interactions evolving into atopic dermatitis. J Allergy Clin Immunol 118: 37-39, 2006.

3. Esparza-Gordillo J, Weidinger S, Fölster-Holst R, Bauerfeind A, Ruschendorf F, Patone G, Rohde K, Marenholz I, Schulz F, Kerscher T, et al: A common variant on chromosome 11q13 is associated with atopic dermatitis. Nat Genet 41: 596-601, 2009.

4. Bieber T: Atopic dermatitis. N Engl J Med 358: 1483-1494, 2008.

5. Leung AK and Barber KA: Managing childhood atopic dermatitis. Adv Ther 20: 129-137, 2003.

6. Cork MJ, Robinson DA, Vasilopoulos Y, Ferguson A, Moustafa M, MacGowan A, Duff GW, Ward SJ and Tazi-Ahnini R: New perspectives on epidermal barrier dysfunction in atopic dermatitis: Gene-environment interactions. J Allergy Clin Immunol 118: 3-21, 2006.

7. Danby SG and Cork MJ: The effects of pimecrolimus on the innate immune response in atopic dermatitis. Br J Dermatol 168: 235-236, 2013.

8. Kim EC, Lee HS, Kim SK, Choi MS, Lee S, Han JB, An HJ, Um JY, Kim HM, Lee NY, et al: The bark of Betula platyphylla var. japonica inhibits the development of atopic dermatitis-like skin lesions in NC/Nga mice. J Ethnopharmacol 116: 270-278, 2008.

9. Choi YY, Kim MH, Han JM, Hong J, Lee TH, Kim SH and Yang WM: The anti-inflammatory potential of Cortex Phellodendron in vivo and in vitro: Down-regulation of No and iNOS through suppression of NF- $\mathrm{KB}$ and MAPK activation. Int Immunopharmacol 19: 214-220, 2014.

10. Park S, Lee JB and Kang S: Topical application of Chrysanthemum indicum L. Attenuates the development of atopic dermatitis-like skin lesions by suppressing serum IgE levels, IFN- $\gamma$ and IL-4 in Nc/Nga mice. Evid Based Complement Alternat Med 2012: 821967, 2012.

11. Xian YF, Mao QQ, Ip SP, Lin ZX and Che CT: Comparison on the anti-inflammatory effect of cortex Phellodendri chinensis and cortex Phellodendri amurensis in 12-O-tetradecanoyl-phorbol-13-acetate-induced ear edema in mice. J Ethnopharmacol 137: 1425-1430, 2011.

12. Gong F, Shen Y, Zhang Q, Sun Y, Tang J, Tao F and Xu Q: Obaculactone suppresses Th1 effector cell function through down-regulation of T-bet and prolongs skin graft survival in mice. Biochem Pharmacol 80: 218-225, 2010.

13. Zhang C: Determination of obacunone and obaculactone in different processing products of Phellodendria murensis cortex. Zhong Yao Cai 36: 205-208, 2013 (In Chinese). 
14. Cai Z, Li W, Wang H, Yan W, Zhou Y, Wang G, Cui J and Wang F: Anti-tumor and immunomodulating activities of a polysaccharide from the root of Sanguisorba officinalis L. Int J Biol Macromol 51: 484-488, 2012.

15. Yu T, Lee YJ, Yang HM, Han S, Kim JH, Lee Y, Kim C, Han MH, Kim MY, Lee J and Cho JY: Inhibitory effect of Sanguisorba officinalis ethanol extract on $\mathrm{NO}$ and $\mathrm{PGE}_{2}$ production is mediated by suppression of NF- $\kappa \mathrm{B}$ and AP-1 activation signaling cascade. $\mathrm{J}$ Ethnopharmacol 134: 11-17, 2011.

16. Hayakawa R: Human closed patch test. Skin Res 26: 1119-1127, 1984 (In Japanese).

17. Zhishen J, Mengcheng T and Jianming W: The determination of flavonoid contents in mulberry and their scavenging effects on superoxide radicals. Food Chem 64: 555-559, 1999.

18. Rao TM, Rao BG and Rao YV: Antioxidant activity of Spilanthes acmella extracts. Int J Phytopharmacol 3: 216-220, 2012.

19. Mills LB, Mordan LJ, Roth HL, Winger EE and Epstein WL: Treatment of severe atopic dermatitis by topical immune modulation using dinitrochlorobenzene. J Am Acad Dermatol 42: $687-689,2000$

20. Kunz B, Oranje AP, Labrèze L, Stalder JF, Ring J and Taïeb A: Clinical validation and guidelines for the SCORAD index: Consensus report of the european task force on atopic dermatitis. Dermatology 195: 10-19, 1997.

21. Ong PY and Leung DY: Immune dysregulation in atopic dermatitis. Curr Allergy Asthma Rep 6: 384-389, 2006.

22. Abramovits W: A clinician's paradigm in the treatment of atopic dermatitis. J Am Acad Dermatol 53 (1 Suppl 1): S70-S77, 2005.

23. Livak KJ and Schmittgen TD. Analysis of relative gene expression data using real-time quantitative PCR and the 2(-Delta Delta C(T)) Method. Methods 25: 402-408, 2001.
24. Matsuda H, Watanabe N, Geba GP, Sperl J, Tsudzuki M, Hiroi J, Matsumoto M, Ushio H, Saito S, Askenase PW and Ra C: Development of atopic dermatitis-like skin lesion with IgE hyperproduction in NC/Nga mice. Int Immunol 9: 461-466, 1997.

25. Takahashi N, Arai I, Honma Y, Hashimoto Y, Harada M, Futaki N, Sugimoto M and Nakaike S: Scratching behavior in spontaneous- or allergic contact-induced dermatitis in $\mathrm{NC} / \mathrm{Nga}$ mice. Exp Dermatol 14: 830-837, 2005.

26. Hashimoto Y, Takaoka A, Sugimoto M, Honma Y, Sakurai T, Futaki $\mathrm{N}$ and Arai I: Itch-associated scratching contributes to the development of dermatitis and hyperimmunoglobulinaemia $\mathrm{E}$ in NC/Nga mice. Exp Dermatol 20: 820-825, 2011.

27. Vailes LD, Perzanowski MS, Wheatley LM, Platts-Mills TA and Chapman MD: IgE and IgG antibody responses to recombinant Alt a 1 as a marker of sensitization to alternaria in asthma and atopic dermatitis. Clin Exp Allergy 31: 1891-1895, 2001.

28. Galli SJ and Tsai M: IgE and mast cells in allergic disease. Nat Med 18: 693-704, 2012 .

29. Grewe M, Bruijnzeel-Koomen CA, Schöpf E, Thepen T, Langeveld-Wildschut AG, Ruzicka T and Krutmann J: A role for Th1 and Th2 cells in the immunopathogenesis of atopic dermatitis. Immunol Today 19: 359-361, 1998.

30. Chen L, Martinez O, Overbergh L, Mathieu C, Prabhakar BS and Chan LS: Early up-regulation of Th2 cytokines and late surge of Th1 cytokines in an atopic dermatitis model. Clin Exp Immunol 138: 375-387, 2004.

31. Yamanaka K and Mizutani H: The role of cytokines/chemokines in the pathogenesis of atopic dermatitis. Curr Probl Dermatol 41: 80-92, 2011. 